\title{
Considerations about Future Community Construction
}

\author{
Yao Qin \\ Zhejiang Agriculture and Forestry University, Hangzhou, China \\ Email: qy814341252@163.com
}

How to cite this paper: Qin, Y. (2020). Considerations about Future Community Construction. Open Journal of Social Sciences, $8,165-173$.

https://doi.org/10.4236/jss.2020.88015

Received: July 28, 2020

Accepted: August 18, 2020

Published: August 21, 2020

Copyright ( 2020 by author(s) and Scientific Research Publishing Inc. This work is licensed under the Creative Commons Attribution International License (CC BY 4.0).

http://creativecommons.org/licenses/by/4.0/

\begin{abstract}
In 2019, Zhejiang Province proposed a pilot work plan for future community construction, which is an innovation that tries to meet the aspirations of the entire community for a better life, to integrate advanced culture and cutting-edge technology, and to lead a high-quality life. After discussing the meaning of the future community, its predecessor, the purpose and vision of future community construction, and combining the impact of the Novel Coronavirus Pneumonia on the community, the paper puts forward that in the future construction, we should comprehensively consider the nine aspects of governance, wisdom, strength, protection, green (low-carbon), support, education, service and efficiency on the people-oriented guidance.
\end{abstract}

\section{Keywords}

Future Community, Older Residential, Quality of Living, People-Oriented

\section{The Definition of Future Community}

"Community" refers to a community of social life formed by people in the same geographic area with the living environment as the main body, which is the basic unit of urban life. Residential space occupies the largest proportion of all types of urban land use, and is the space with the largest land area in the city, whose governance importance is unquestionable.

In 2019, Zhejiang Province formally issued the Zhejiang Future Community Construction Pilot Work Plan, which clearly explained the connotation of the future community and proposed the "139" top-level design (Zhe, 2019) shown in Figure 1. Specifically, it is centered on the people's aspiration for a better life, human-oriented, ecological, and digital as the value orientation, with harmony and co-governance, green intensive, and wisdom sharing as the basic connotations, to 


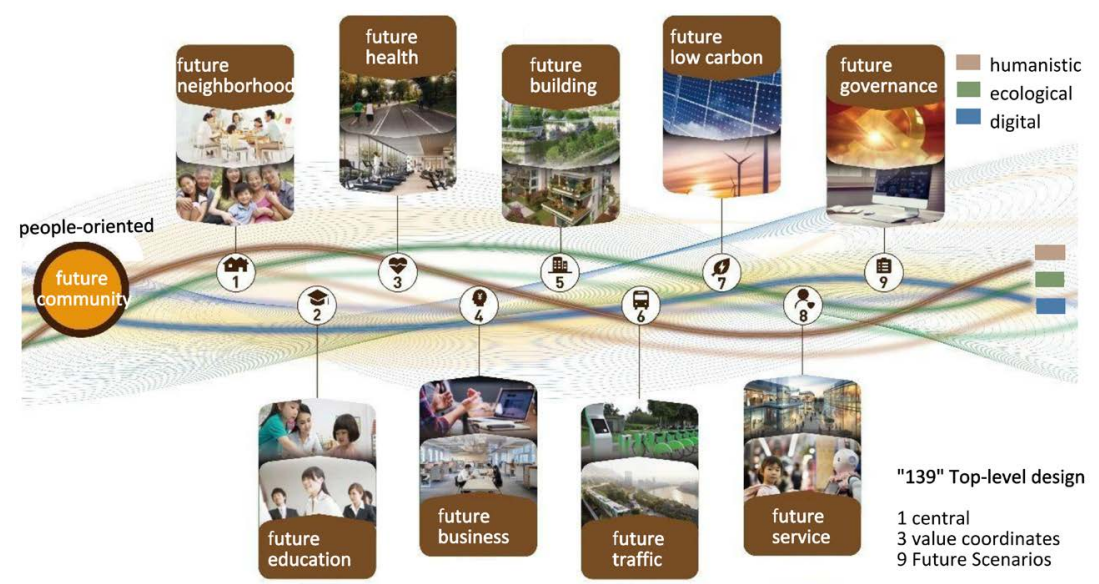

Figure 1. "139" top-level design of Zhejiang future community. Photos source: http://www.keyhouse.com.cn/xw/2020/4/81242.shtml.

build future neighborhoods, education, health, entrepreneurship, the nine scenarios of construction, transportation, low-carbon, service and governance create new urban functional units with a sense of belonging, comfort and future.

Future communities are an international hot-spot. Canada is building the future community of Quayside, trying to build a smarter, greener and inclusive city. The European BLOCK model, Singapore COMPLEX model, and Japanese shared housing can also see the shadow of future communities. These models point to a common direction; that is, with the deepening of national scientific and technological development and industrial transformation, as the basic unit of the city, what kind of looks should the community own to undertake the implementation of new things and new technologies, and how to become more humanistic and the "Future community" are the answers to the regional space that improves the quality of living.

Generally speaking, the future community is also dominated by the living environment, but compared with the traditional community, it is a more convenient, safe and comfortable living environment for residents. For the city, it is a kind of tool which is conducive to building a comprehensive, accurate scientific urban management, and to achieve the goal of building a beautiful, low-carbon, and smart city.

\section{The Purpose and Vision of the Future Community}

\subsection{The Integration to Solve People's Livelihood Pain Points}

In the "139" top-level design framework of Zhejiang Future Community, "1", means centering on people's yearning for a better life is the ultimate goal and vision, and the future community is an integrated solution to people's livelihood pain points. In December 2018, the Zhejiang Provincial Development and Reform 
Commission took the lead in launching a questionnaire survey on future community construction, and received more than 30,000 valid questionnaires. The results of the questionnaire showed that the concentration of public opinion is mainly in these including areas-real estate that is more important than humanities, indifferent and lacking neighbor relations, cultural exchange carrier platform, difficulty in nursery and childcare, scarcity of high-quality educational resources, limited coverage, and the "affordable" but "not good" community medical care, lacking elderly facilities and services, diverse health needs that are difficult to meet, difficult parking, inconvenient public transportation, and not perfect logistics and distribution services. These answers showed the people's yearning for a better life and the requirements for the living environment. In the future, the community will be problem-oriented and try to create a more livable, workable urban unit that is satisfied with the people.

\subsection{The Renovation and Upgrade of Old Urban Communities}

Hangzhou City proposes to make the comprehensive transformation of old communities an important part of the city's organic renewal. The comprehensive transformation of old communities and future community pilot projects are being promoted simultaneously (Li \& Huang, 2019). The construction of future communities provides an opportunity for the transformation of old communities, and the transformation of old communities also provides pilot opportunities for future community construction. Directly connecting the reconstruction of the old community with the construction of the future community, skipping the intermediate steps of the reconstruction or reconstruction of a large number of old communities before proceeding to the future community construction can save a lot of manpower and material resources, and can make the living environment in the city the worst have been improved and promoted.

At present, most of the future community pilots in Zhejiang Province are old communities. On the one hand, it can improve people's livelihood, and on the other hand, it can revitalize existing assets and release the potential of assets. After the renewal and transformation of future community projects, the value of old houses will appreciate rapidly, the pressure of households to replace new houses is reduced, or their willingness will be replaced, the entire market is further revitalized.

\subsection{Facilitating the Introduction of Urban Talents}

Future communities that are livable and prosperous will help cities attract talents. In addition to having a high-quality living environment, future entrepreneurship scenarios in the future community will be enhanced through "sounding the mechanism of characteristic talent settlement", "creating a good ecosystem for community innovation and entrepreneurship", and "promoting the comprehensive sharing of community resources, skills, and knowledge”, which can increase the attraction of talent. In the future, the first batch of 24 pilot 
projects in the community plans to introduce 62,700 talents of various types, which will provide talent guarantee for urban development.

\subsection{Promoting the Implementation of Cutting-Edge Technologies}

In the future, community decision-making will promote the large-scale application of cutting-edge technologies such as digital intelligence, energy conservation and environmental protection, and green buildings, which will promote the emergence of a large number of new business forms and models, and will drive the development of related industries. A variety of technical resources will be integrated into the scenarios envisaged by the future community, integrating various industries, and activating resources in various fields, thereby stimulating a large amount of investment. For example, Hangzhou City plans to invest 105.9 billion yuan in the first batch of seven future community pilot projects. This alone accounted for about 7.9\% of Hangzhou's 2018 annual GDP (1.346778 billion). In the future, the community will be fully replicated and promoted in the whole province of Zhejiang, and the magnitude of the investment drive cannot be underestimated.

\section{The Predecessor of the Future Community- "Old Community"}

The old community refers to the city that has been built for a long time and is still in use today, but the construction standards are not high, the use of functions is incomplete, and their supporting facilities are not complete. There are hidden safety hazards in disrepair, the lack of property services, which it cannot satisfy people's normal or high life residential districts in demand (Cai, Yang, \& Li, 2017). They are parts of a city that must be transformed and upgraded. In the old communities from the 1970s to the 1990s, so far, most of these communities lack or do not have property management, few or dilapidated supporting facilities, prominent security risks, backward building materials and close to the service life, and the exterior is dilapidated and dilapidated, which is incompatible with the environment. Figures 2-5 show the XYY community, an older neighborhood in Hangzhou.

The XYY community in Hangzhou was originally a resettlement building for two provincial-level units in the 1990s, and later merged into a community. The community has typical characteristics of an old community: no property management; lack of living facilities due to demolition around; road potholes and narrow, difficult for fire trucks to enter; no parking lot, multiple private cars make the road narrower; residential buildings are standing outside; the surface is broken; the old circuits and pipelines have safety hazards. The renewal of old communities has always been fragmented, and often only partial and fragmented renovations are carried out. When the funds are down, they will "treat headaches and foot pains", and the community environment will be renovated, which cannot meet the residents' growing yearning for a better life. 


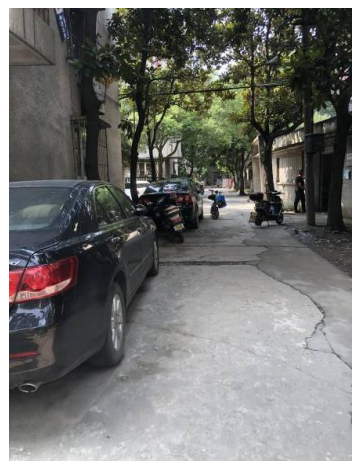

(a)

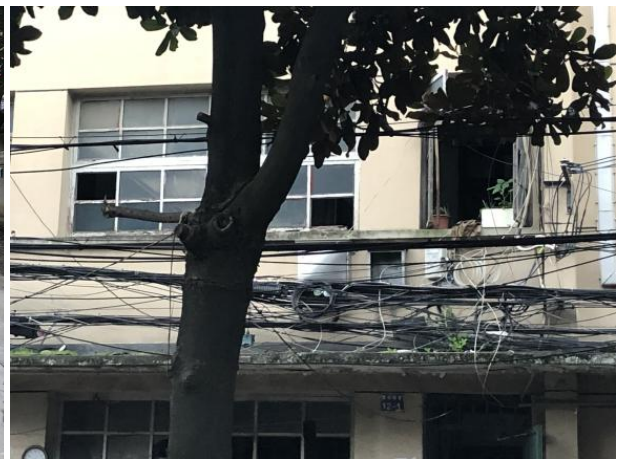

(b)

Figure 2. Vehicles invaded the road and cables are messy.

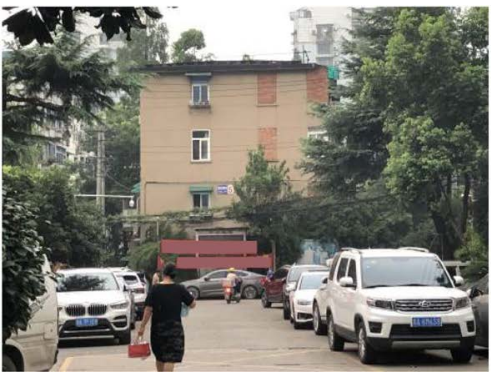

(a)

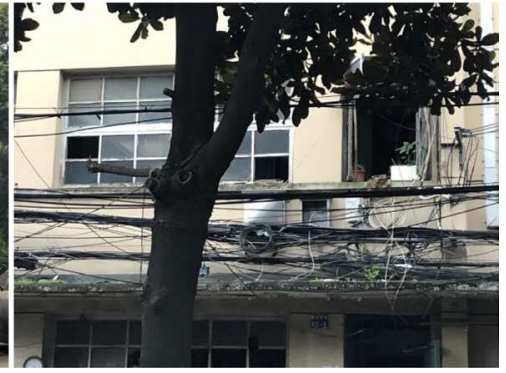

(b)

Figure 3. Dilapidated building facade and abandoned public green space.

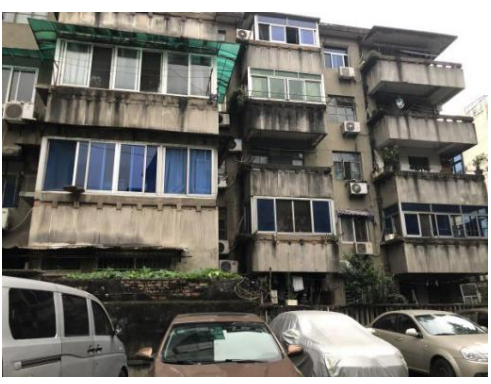

(a)

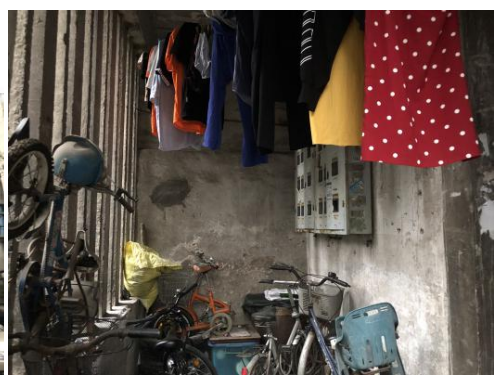

(b)

Figure 4. The building's messy facade and the internal public space is messy.

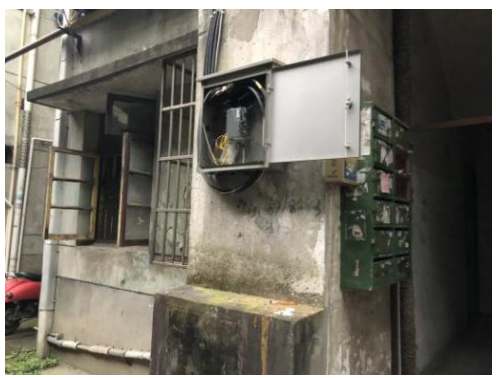

(a)

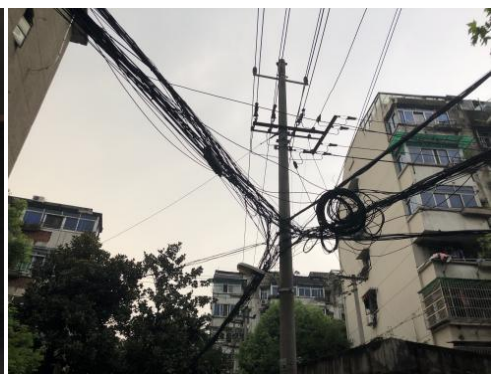

(b)

Figure 5. Bare electrical accessories and messy cables.

There are various problems in such communities, which affect the quality of life of residents and the image of the city, but they can do two things with one 
stone to undertake the construction of future communities in situ, providing geographic space and construction ideas for problem-oriented future communities.

\section{The Considerations for Future Community Construction}

Regarding the construction of future communities, some scholars have generally proposed that, in contrast to "139" the existing model of community construction in Hangzhou is fragmented, with the phenomenon of "all departments working on their own, and departments fighting alone”. Social forces and grassroots people, the subjectivity of the government is not fully exerted, and the level of resource integration is still not high (Lang, 2019). In summary, from the perspective of architectural scenes, architectural scenes serve as the "containers" of other scenes. They are the basic material space and external performance. The human settlement environment scale and community living circle are proposed for the systematic design of future community architectural scenes. This basic principle (Song, 2019) is related to neighborhoods, transportation, education, etc. From the perspective of public services, in future community construction, attention should be paid to the rights and interests of persons with disabilities, and barrier-free communities should be built to accommodate various groups including persons with disabilities and encourage them to participate comfortably in activities and provide them with satisfactory services (Li, 2019). This perspective is related to scenarios such as health and governance. From the perspective of smart services, a model of domestic future community construction, the highly digitalized modern community "Lianhua Five Village Digital Community" reflects that smart construction is a "new wave" (Ma, 2019), which is very important for future communities. The development of the nine major scene applications is of great value, but in actual applications, there are still problems such as imperfect APP construction, lack of care for the elderly, and potential safety hazards. In addition, some scholars have made ideas for future community development in terms of three-dimensional community greening, garbage classification, and energy-saving effects. In connection with the 2020 Novel Coronavirus Pneumonia, the author believes that future community construction should comprehensively consider the nine points of governance, wisdom, strength, protection, greenness, support, education, service, and efficiency.

\subsection{Governance}

The allocation of human resources for community cadres should be paid more attention. First, the number should be appropriately increased. The epidemic has exposed a shortage of community workers. Secondly, the quality of community cadres also needs to be improved, with high-quality talents or special talents engaged in community management affairs. This may also cause adjustments in community institutions, increased functions, staffing and training, etc. In the 
early stage of community construction in the future, regular surveys and evaluations are needed.

\subsection{Wisdom}

Future communities and smart communities are not equated. Smart communities rely on large-scale use of technology. Strictly speaking, future communities include smart communities, and the smart scenarios of future communities must be guaranteed by technology. In the conception, smart devices and systems throughout the community need mature, unified, and coordinated technology and humanized design, otherwise the crowd will not experience the benefits of smart scenes, and smart scenes may become a "vase" that cannot be used.

\subsection{Strength}

It needs encouraging the decentralization of part of the city's management authority to the community and increasing the power of the community. For example, in this epidemic, the community's power as a "small door" defense line requires community residents to self-isolate, controls their free travel, and other powers to impose corresponding punishments on people and behaviors that endanger public safety and order.

\subsection{Protection}

The first is to protect the daily personal safety of community residents. The current main concept of community security is to monitor pedestrians and vehicles entering and leaving the community and in the community through a large number of monitoring equipment and community IoT applications. Second, in the face of sudden public safety incidents, the design of the community needs to have blank areas to increase the versatility and adaptability of the community in the future. For example, some scholars advocate the establishment of community libraries and other places to help avoid disasters when emergencies occur. Then there is the protection of the privacy and security of residents' data, and it is necessary to achieve a balance between informatization and security of the Internet of Things.

\subsection{Green (Low Carbon)}

Green and low-carbon scenarios, include electricity, water treatment, transportation, buildings, etc. For outdoor use, we can learn from Singapore's experience in transportation and equip with a large area of green belts to bring a quiet living environment. In terms of buildings, considering three-dimensional greening, and green buildings that save materials to the greatest extent throughout their lifespan. Regarding the indoor environment, according to nearly 100,000 surveys conducted by relevant scholars, in the face of sudden epidemics, residents pay much more attention to the indoor environment than to outdoor public spaces. Therefore, it is necessary to embed green technology in residential spaces, such as MOMA, MOMA Technology (Yang \& Gao, 2013). 


\subsection{Support}

The future community is not an isolated module. It is necessary to strengthen the linkage between residents, between communities, and between communities and social organizations and social work agencies. For residents, it is necessary to create a concept of community and enhance neighborhood interaction. In this epidemic, some scholars have suggested that some social organizations have made great contributions to the prevention and control of the community's epidemic situation and services for the needy in the community. Therefore, to play the role of social organizations thoroughly and social work institutions, the "pairing" model can be adopted to maintain contact and support each other in terms of personnel, materials, and services.

\subsection{Education}

In the prevention and control of the epidemic, a few residents did not understand or even abused community workers, believing that the prevention and control of the epidemic was a government matter and had nothing to do with them, which did not reach a consensus on the community's anti-epidemic work. Fundamentally speaking, these contradictions and problems reflect the lack of community spirits. In addition to cultivating the spirit of community, the community will have more wisdom scene teaching and daily science education in the future.

\subsection{Service}

The specific hardware and software services provided by the community in the future are mainly determined by the type of community. In the planning and construction of future communities, some of the original communities will be demolished and reconstructed, and some will be reconstructed. At present, the construction cost of the future community is relatively high, and the needs and acceptance of different types of community groups are not the same. For example, communities with more elderly or sick and disabled people need more restrictive conditions in health scenarios. Those with more employed youths are more comprehensive in entrepreneurship scenarios than other communities. Therefore, it is necessary to focus on key points and gradually implement construction plan to avoid "one size fits all", which is also conducive to shaping community characteristics and promoting the diversification, differentiation and specialization of future community models.

\subsection{Efficiency}

In order to improve management efficiency, new tools can be used, for example, establishing a community public safety event database, including community-prone events, emergencies, man-made events, etc., and preparing for corresponding emergency plans. For a long time, the community has always followed the instructions issued by the superiors and cannot make a decision in the first 
time. However, the community is densely populated with strong communication, which is necessary to respond to the security incident in the first time.

\section{Conclusion}

The future community is an important step in urban management; it has an immediate effect in solving the pain points of people's livelihood, transforming and upgrading old urban residential areas, facilitating the introduction of urban talents, and promoting the implementation of cutting-edge technologies. Therefore, in the process of design and construction, the nine points of governance, wisdom, strength, protection, green, support, education, service, and efficiency should be considered. In terms of governance, it is necessary to improve the allocation of human resources; in the application of wisdom, it is necessary to prevent future community construction from becoming a "vase"; in terms of protection, it is necessary to balance the relationship between informatization and security, and to promote indoor and outdoor in green. It is necessary to be good at "pairing" in support ability, to create a community spirit in education, to prevent the construction process from being "one size fits all" in terms of service, to use the courage to adopt new tools in terms of efficiency, and to prevent all communities from being the same without characteristics. "On the social side", the final goal is to improve the living quality of the old community, and everything is people-oriented.

\section{Conflicts of Interest}

The author declares no conflicts of interest regarding the publication of this paper.

\section{References}

Cai, Y. N., Yang, X. J., \& Li D. L. (2017). “Micro-transformation”: The Renewal Method of Old Urban Community. Urban Development Studies, 24, 29-34.

Lang, X. B. (2019). Reflections on Promoting the Construction of "Future Community" in Hangzhou. Hangzhou, No. 39, 50-52.

Li, M. C., \& Huang, C. X. (2019). Future Community: Based on the Current, Future-Oriented Old Community Reconstruction. Hangzhou (Weekly), No. 32, 38-41.

Li, W. C. (2019). Inclusion and Service of the Disabled in Future Community Construction. Social Welfare, No. 9, 30-32+51.

Ma, J. J. (2019). Exploration of Operation and Maintenance Approaches for Future Intelligent Community Construction. Intelligent City, 5, 1-3.

Song, W. (2019). Architectural Scene Design of Future Community. Zhejiang Economy, No. 21, 22.

Yang, Y., \& Gao, Y. B. (2013). The Application of Constant Temperature, Constant Humidity and Constant Oxygen System in the Residence of Taiyuan-Take Taiyuan Wanguo MOMA as an Example. Applied Mechanics and Materials, 2547, 480-483. https://doi.org/10.4028/www.scientific.net/AMM.361-363.480

Zhe, Z. F. (2019). NO. 8. Zhejiang Province Future Community Construction Pilot Work Plan. http://www.keyhouse.com.cn/xw/2020/4/81242.shtml 